\title{
Chemical treatment of the intra-canal dentin surface: a new approach to modify dentin hydrophobicity
}

\author{
Cesar GAITAN-FONSECA ${ }^{1}$, Pierre-Yves COLLART-DUTILLEUL ${ }^{2}$, Vincent SEMETEY ${ }^{3}$, Olivier ROMIEU ${ }^{4}$, Roel CRUZ $^{5}$, \\ Hector FLORES ${ }^{6}$, Frédéric CUISINIER ${ }^{7}$, Elías PÉREZ ${ }^{8}$, Amaury POZOS-GUILLEN ${ }^{9}$
}

\author{
1- DDS, MSc, Institutional Doctorate in Engineering and Science Materials, Universidad Autónoma de San Luis Potosí, San Luis Potosí, México \\ 2- DDS, MSc, Laboratoire Biosanté et Nanoscience, Montpellier, France. \\ 3- PhD, Institut Curie, Centre de Recherche, Paris, France. \\ 4- DDS, MSc, Laboratoire Biosanté et Nanoscience, Montpellier, France. \\ 5- PhD, Institutional Doctorate in Engineering and Science Materials, Universidad Autónoma de San Luis Potosí, San Luis Potosí, México. \\ 6- DDS, PhD, Institutional Doctorate in Engineering and Science Materials, Universidad Autónoma de San Luis Potosí, San Luis Potosí, México. \\ 7- DDS, PhD, Laboratoire Biosanté et Nanoscience, Montpellier, France. \\ 8- PhD, Institutional Doctorate in Engineering and Science Materials, Universidad Autónoma de San Luis Potosí, San Luis Potosí, México. \\ 9- DDS, PhD, Institutional Doctorate in Engineering and Science Materials, Universidad Autónoma de San Luis Potosí, San Luis Potosí, México.
}

Corresponding address: Amaury de J. Pozos-Guillen - College of Stomatology - Universidad Autónoma de San Luis Potosí - Laboratory of Basic Sciences - Manuel Nava 2 - Zona Universitaria - 78290 - San Luis Potosí - SLP - México - Phone: + 524448262357 X 114 - Fax: + 524448139743 - e-mail: apozos@ uaslp.mx

Received: February 26, 2012 - Modification: January 03, 2013 - Accepted: January 19, 2013

\section{ABSTRACT}

$\mathrm{O}$ bjective: This study evaluated the hydrophobicity of dentin surfaces that were modified through chemical silanization with octadecyltrichlorosilane (OTS). Material and Methods: An in vitro experimental study was performed using 40 human permanent incisors that were divided into the following two groups: non-silanized and silanized. The specimens were pretreated and chemically modified with OTS. After the chemical modification, the dentin hydrophobicity was examined using a water contact angle measurement (WCA). The effectiveness of the modification of hydrophobicity was verified by the fluid permeability test (FPT). Results and Conclusions: Statistically significant differences were found in the values of WCA and FPT between the two groups. After silanization, the hydrophobic intraradicular dentin surface exhibited in vitro properties that limit fluid penetration into the sealed root canal. This chemical treatment is a new approach for improving the sealing of the root canal system.

Key words: Dentin. Surface properties. Octadecyltrichlorosilane.

\section{INTRODUCTION}

Micro-leakage directly affects the results of the root-canal treatment. Complete obturation of the root-canal with an inert filling material to create an apical seal has been proposed as the goal for successful endodontic treatment. However, microleakage can occur and is the primary cause of endodontic treatment failure. In cases of endodontic treatment failure, the probabilities of retreatment or surgical success range from $84 \%$ to $92 \%$, depending on the material used (Super EBA or MTA) and the technique used (conventional or microsurgery) ${ }^{10}$.
Nevertheless, the literature suggests that persistent intra-radicular infection and further leakage are the major causes of endodontic treatment failure ${ }^{21}$.

Root canal obturation involves the threedimensional filling of the entire root canal system; this procedure is a critical step in endodontic therapy. Root canal obturation serves the following two purposes: the elimination of all sources of leakage from the oral cavity or peri-radicular tissues into the root canal system, and the sealing of any remaining irritants within the root canal system after appropriate shaping and cleaning of the canals ${ }^{8}$. The importance of three-dimensional obturation of 
the root canal system cannot be overstated; the achievement of this goal depends primarily on the quality of the canal cleaning and shaping as well as on the clinical skills of the professional who performs the procedures. The other factors that influence the final success or failure of endodontic treatment in each case include the materials used and the method in which they are used $1,3,14,16,21$.

The term monoblock has become a familiar term in endodontic literature with a recent interest in the application of dentin adhesive technology to endodontics. The obturation monoblocks created in the root canal spaces can be classified as primary, secondary or tertiary, depending on the number of interfaces between the bonding substrate and the bulk material core. A primary monoblock has only one interface, which extends circumferentially between the material and the root canal wall. Secondary monoblocks are those that have two circumferential interfaces, one between the cement and dentin and the other between the cement and the core material. Tertiary monoblocks are those in which a third circumferential interface is introduced between the bonding substrate and the abutment material. It is clear from the objectives of the root canal treatment that the most critical area is the apical region of the root canal ${ }^{24}$. A monoblock is created when the canal space becomes perfectly filled with a gap-free, solid mass that consists of different materials and interfaces and improves the sealing of the root canal system.

The strategy of modifying the surface properties of the intra-radicular dentin to achieve the ideal goal of a monoblock in the root canal space with different materials is still a major challenge. The strategy is to modify the hydrophilic condition to prevent apical permeability of the fluid. Romieu, Zimányi and Warszyński²0 (2010) have modeled the penetration of fluid; in this study, they showed the efficiency of hydrophobic surfaces in preventing water penetration into the sealed root canals. Wetability is usually determined by the water contact angle (WCA), and it depends on the molecular forces between the water, the interface, and the chemical nature of the surfaces. Solid surfaces are classified as superhydrophilic, hydrophilic, hydrophobic and superhydrophobic, according to the WCA values ${ }^{11}$. The WCA has been used to evaluate the wetting behavior of root canal sealers and the wetability of composite resins to ascertain the good wetting of tooth surfaces for achieving adhesion ${ }^{15,26}$.

This study evaluated the hydrophobicity of dentin surfaces that were modified through chemical silanization with octadecyltrichlorosilane (OTS).

\section{MATERIAL AND METHODS}

\section{Sample preparation}

For the surface characterization, 40 human incisors that were recently extracted for surgical or periodontal reasons were collected and then stored in a $0.1 \%$ sodium azide $\left(\mathrm{NaN}_{3}\right)$ solution (Sigma-Aldrich, Paris, France) ${ }^{9}$. The dental crowns were sectioned and 3-mm-thick, radicular dentin slices were obtained using a low-speed cutting machine (Isomet, Buehler, Lake Bluff, IL, USA) under copious water cooling. These slices were randomly divided into the following two experimental groups (10 samples each): non-silanized and silanized. Both groups were evaluated based on the WCA measurements and fluid permeability tests (FPT).

\section{Pretreatment protocol}

All of the specimens were pretreated as previously reported to eliminate the smear layer and expose the collagen fibers ${ }^{4}$. Briefly, the specimens were immersed for 3 minutes in $17 \%$ ethylenediamine-tetraacetic acid (EDTA) (J.T. Baker, Mexico City, Mexico) solution, washed with distilled water, immersed for 5 minutes in a $2.5 \% \mathrm{NaOCl}$ (J.T. Baker) solution, again washed with distilled water, again immersed for 3 minutes in the EDTA solution, and washed with distilled water. The specimens were examined at $\times 3,100$ and $\times 5,500$ magnifications under a scanning electronic microscope (SEM) (JEOL LUV 5900, Tokyo, Japan) to assess the elimination of the smear layer and the exposure of collagen fibers, respectively.

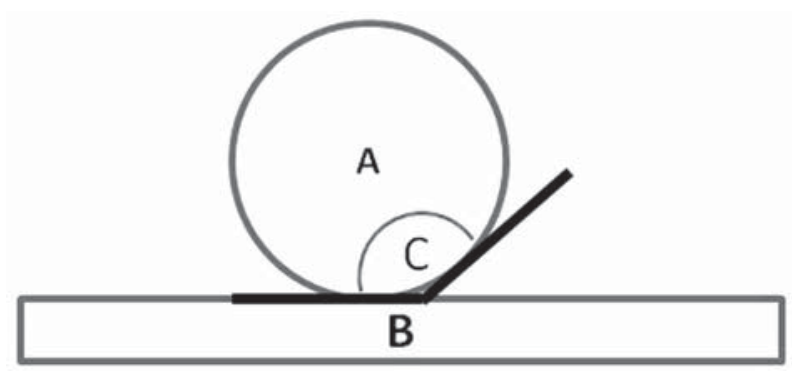

Figure 1- The WCA diagram. This image is representative of the silanized group for observing the obtained hydrophobic characteristics of the intra-radicular dentin surface. A: water drop, B: intra-radicular dentin, C: contact angle measurement

Table 1- The mean values of contact angles (Mean \pm SD)

\begin{tabular}{cc}
\hline Group & Mean \pm Standard Deviation \\
\hline Silanized & $116^{\circ} \pm 5^{\circ}$ \\
Non-silanized & $48^{\circ} \pm 16^{\circ *}$ \\
\hline
\end{tabular}

( ${ }^{*}$ Statistically significant $p<0.05$ ). 


\section{Silanization protocol}

After pretreatment, the specimens underwent silanization by the immersion of each specimen for 1 minute each in $20 \mathrm{~mL}$ distilled water, then $20 \mathrm{~mL}$ ethanol (Fermont Chemicals, Monterrey, Mexico) and finally $20 \mathrm{~mL}$ ethyl acetate (J.T. Baker). Afterwards, the specimens were immersed for 1 minute each in an $86 \%$ octadecyltrichlorosilane (OTS) $(100 \mu \mathrm{L})$ (Fluka, Sigma Aldrich, Switzerland) solution in ethyl acetate $(10 \mathrm{~mL})$, then in ethyl acetate alone $(20 \mathrm{~mL})$ and finally in ethanol $(20 \mathrm{~mL})$.

\section{Water contact angle measurement}

The WCA of the dentin surfaces was measured by the sessile drop technique using a DGD-DX model analysis system (GBX Scientific Instruments, Valence, France). One drop (4 $\mu \mathrm{L})$ of distilled water was deposited on each dentin surface with a micro-syringe (Figure 1). Images were captured immediately after the deposition using a microvideo system (GBX). The acquired images were analyzed by the Visiodrop software (GBX). The WCA values were analyzed by the Wilcoxon test; the statistical significance was set at $p<0.05$.

\section{Fluid permeability test}

Recently extracted uniradicular teeth were used. The crowns were sectioned to obtain a standard tooth root length of $10 \mathrm{~mm}$. Patency of the root canal was achieved with a $21-\mathrm{mm}$ file, type $\mathrm{K} \# 10$; the working length was reached at $0.5 \mathrm{~mm}$ from the apex. The root canal was reamed with the ProTaper Universal system until its size corresponded to that of an F3 instrument. For irrigation, $2.0 \mathrm{~mL}$ of $5.25 \%$ $\mathrm{NaOCl}$ was used at the change of each instrument; a final irrigation was performed with $5 \mathrm{~mL}$ of $17 \%$ EDTA. All of the specimens were obturated using gutta-percha with RoekoSeal (Coltène Whaledent, Cuyahoga Falls, Ohio, USA) as a sealer. For the FPT, the external surfaces of the root were sealed with nail varnish, except for the apical third. The FPT was performed using a closed pressure system under a constant pressure of $3 \mathrm{psi}^{27}$. This pressure was applied with nitrogen for 16 minutes. An air bubble was introduced with a syringe and it was positioned in the millimeter ruler. The FPT was performed by measuring the path of advancement of the air bubble, and the reading was converted to $\mu \mathrm{L} / \mathrm{min}^{-1}$ using the linear velocity formula, $V=\pi(r)^{2}$. L. The FPT values were analyzed by the Wilcoxon test; the statistical significance was set at $\mathrm{p}<0.05$.

\section{RESULTS}

Figure 2 shows the SEM images after pretreatment. As observed in Figure 2A, the smear layer and debris were effectively eliminated by pretreatment. The presence of collagen fibers was also confirmed by the SEM image, as shown in Figure 2B. Table 1 shows the means and standard deviations of the WCAs of the dentin surfaces in the non-silanized and silanized groups. The contact
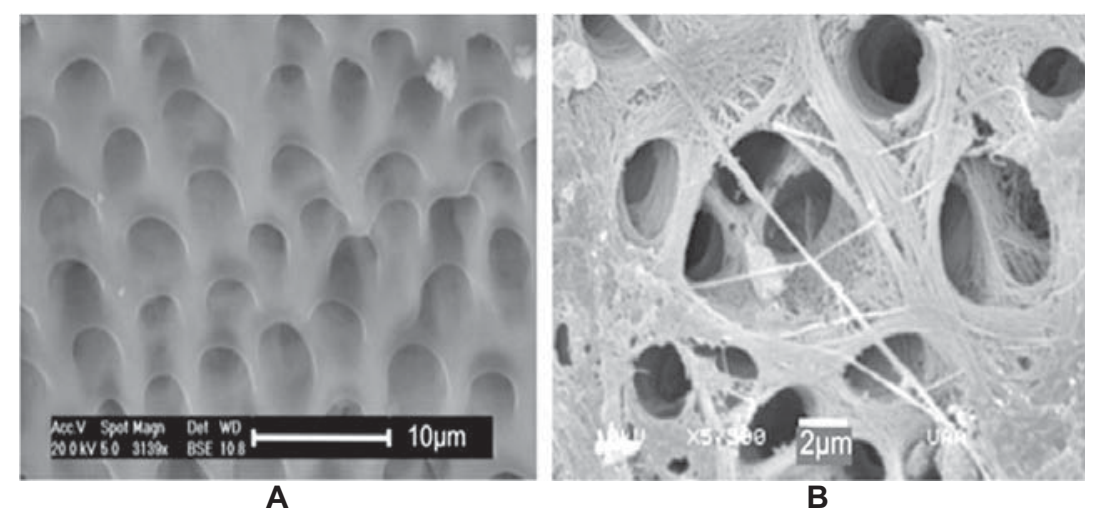

Figure 2- The scanning electron micrography (SEM) image of the pretreated dentin surfaces: A- shows open dentinal tubules and the absence of the smear layer at a magnification of $x 3,100$; B- shows collagen fibers on the dentin surface at x5,500 magnification

Table 2- The values for liquid flow at 16 min of evaluation

\begin{tabular}{cccccc}
\hline Group & $\mathbf{2} \mathbf{m i n}$ & $\mathbf{4} \mathbf{~ m i n}$ & $\mathbf{6} \mathbf{~ m i n}$ & $\mathbf{8} \mathbf{~ m i n}$ & $\mathbf{1 6} \mathbf{~ m i n}$ \\
\hline Silanized & $0.013 \pm 0.0013$ & $0.013 \pm 0.0012$ & $0.007 \pm 0.0002$ & $0.005 \pm 0.0001$ & $0.001 \pm 0.0001$ \\
Non-silanized & $0.039 \pm 0.0021$ & $0.026 \pm 0.0012$ & $0.026 \pm 0.0012$ & $0.013 \pm 0.0011$ & $0.005 \pm 0.0001$ \\
\hline
\end{tabular}

Values represent the mean of 3 samples; data are expressed in $\mu \mathrm{L} / \mathrm{min}^{-1}$. 
angles were significantly higher after treatment with OTS $(p<0.05)$, thereby showing a decreased wettability of the modified surfaces.

The liquid flow was assessed for 16 minutes (at 2, 4, 6, 8 and $16 \mathrm{~min}$ ). The FPT showed a liquid flow of $0.3264 \pm 0.0123 \mu \mathrm{L} / \mathrm{min}^{-1}$ through the non-silanized root canals and a liquid flow of $0.1172 \pm 0.005 \mu \mathrm{L} / \mathrm{min}^{-1}$ through the silanized samples. These values represent the total liquid flow at all times in each group. The difference in the total liquid flow between the two groups was statistically significant $(p<0.05)$. These results are shown in Table 2.

\section{DISCUSSION}

This study was focused on the modification of the intra-radicular dentin surface with OTS in ethyl acetate solvent after chemical pretreatment. OTS is the most effective silanizing agent that is used for the production of hydrophobic surfaces. OTS has been extensively used in semiconductors, bio-membrane models, nanolithography, infrared spectroscopy and Raman spectroscopy ${ }^{5,25}$.

In dentistry, silanes have been used to coat the inorganic filler particles on polymer matrix composites and for adhesive bonding to resin and luting porcelain cements in restorative procedures ${ }^{13,18}$. Silanization is also performed for post collocation in endodontics, where silanes are coated on the surface of the post for repelling water, blood and saliva ${ }^{23,29}$. We report a new approach to the modification of the intra-radicular dentin surface by converting it to a hydrophobic surface to improve root canal sealing. There are a few reports that focused on changing the properties of an intraradicular dentin surface ${ }^{12,22}$.

In this study, subsequent treatments were performed to modify the intra-radicular dentin surface. First, we carried out a pretreatment with EDTA (17\%) and $\mathrm{NaOCl}(2.5 \%)$ solutions. Further, the effectiveness of EDTA concentrations in the range of $15 \%-24 \%$ within a period of less than 8 minutes for preventing cell necrosis and maintaining the integrity of the collagen was demonstrated. The use of a $2.5 \%$ concentration of $\mathrm{NaOCl}$ for less than 1 hour was shown to cause minor changes in the collagen fibers ${ }^{30}$. The intra-radicular dentin was not damaged at these concentrations and exposure times, and the integrity of the collagen fibers was conserved and they remained functional for chemical interaction with the OTS.

The WCA measurement determined the wetability of the surface. A surface is considered to be hydrophobic when the contact angle is over 90 degrees ${ }^{11,20}$. The hydrophobicity of the intraradicular dentin surface was assessed by the WCA measurements before and after the chemical modification. The pretreatment group showed an average contact angle of $48^{\circ} \pm 16^{\circ}$, which indicates the original hydrophilic nature of the intra-radicular dentin. After silanization, the average contact angle was $116^{\circ} \pm 5^{\circ}$, thereby indicating the hydrophilic to hydrophobic transformation of the intra-radicular dentin surface.

The purpose of this procedure is to allow the OTS to react chemically with the collagen fibers and hydroxyapatite (HA). The chemical interaction between the OTS and the dentin takes place in HA and the collagen fibers. In $22 \%$ of the interactions in the collagen, the principal amino acids for that chemical interaction are glycine, proline and hydroxyproline. OTS interacts with the phosphates in $\mathrm{HA}$, creating the $\mathrm{P}-\mathrm{O}-\mathrm{Si}$ bonds, and in the collagen fiber trough, the hydroxyl group $(\mathrm{OH})$ creates the $\mathrm{Si}-\mathrm{O}$ bonds $^{28}$.

The fluid filtration technique has been used to measure micro-leakage since $1988^{17}$, and various studies have used radioisotopes, dyes, fluids and bacterial growth to evaluate apical leakage as the possible cause of endodontic treatment failure ${ }^{2,19}$. The effectiveness of hydrophobic modification was verified by the FPT. In this test, the water flow was directed towards roots that had undergone a hydrophobic chemical treatment, and the opening was sealed with gutta-percha and RoekoSeal. After polymerization and cross-linking, the solid RoekoSeal samples exhibited an external hydrophobic surface, and they did not allow aqueous solvents to infiltrate and swell the material. Therefore, RoekoSeal can be used in combination with water without inducing material deformation, indicating that this compound is an ideal complement for use with the dentin surface treatment ${ }^{7}$. The FPT results indicated that the modified surface effectively reduced the water flow; this result is important to avoid fluid micro-filtration. In previous reports, all of the FPTs were performed under hydrophilic conditions to evaluate the techniques and materials for endodontic obturation $3,9,16$. These studies have reported fluid permeability values under hydrophilic conditions that range from $0.50 \mu \mathrm{L} / \mathrm{min}-1$ to 0.26 $\mu \mathrm{L} / \mathrm{min}-1$, depending on the obturation technique used. In our study, the fluid permeability value under hydrophobic conditions was $3.09 \times 10-5 \mu \mathrm{L} /$ min-1. These results show that the hydrophilic-tohydrophobic chemical transformation is effective in reducing the fluid permeability ${ }^{6}$.

The silanization process has some disadvantages due to the possible cytotoxicity of the solvents used and sub-products derived from the chemical reaction. The proposed chemical modification of the intra-radicular dentinal surfaces is a new strategy in the prevention of apical leakage and could be an alternative approach for achieving a better clinical prognosis. The next step is to perform an 
in vivo study to confirm the absence of toxicity in the periapical region and improved effectiveness in preventing endodontic treatment failure.

\section{CONCLUSIONS}

The intra-radicular dentinal surface was effectively modified into a hydrophobic surface by chemical silanization with OTS. The hydrophobic dentinal surface exhibited in vitro properties that limit fluid permeability into the root canal, which was sealed using a lateral gutta-percha condensation and silicon-based sealer. This chemical treatment is a new approach for improving the sealing of the root canal system.

\section{ACKNOWLEDGEMENTS}

This work was supported by PCP FranceMexico, PIFI 2011-12, CONACYT 162651, PROMEP/ UASLP/12/CA14, and C12-FAI-03-45.45 grants. Cesar Gaitan is a CONACYT fellow 290541. We would like to thank American Experts, for their assistance in editing this manuscript.

\section{REFERENCES}

1- Barbizam JV, Souza M, Cecchin D, Dabbel J. Effectiveness of a silicon-based root canal sealer for filling of simulated lateral canals. Braz Dent J. 2007;18:20-3.

2- Bergenholtz G, Spångberg L. Controversies in Endodontics. Crit Rev Oral Biol Med. 2004;15:99-114.

3- Cobankara FK, Adanir N, Belli S, Pashley DH. A quantitative evaluation of apical leakage of four root-canal sealers. Int Endod J. 2002;35:979-84.

4- Dutilleul PYC, Fonseca CG, Zimányi L, Romieu O, Pozos-Guillen $\mathrm{AJ}$, et al. Root canal hydrophobization by dentinal silanization: improvement of silicon-based endodontic treatment tightness. J Biomed Mater Res Part B. 2012. In press.

5- Elmore DL, Chase DB, Liu Y, Rabolt JF. Infrared spectroscopy and spectroscopic imaging of n-propyl trichlorosilane monolayer films self-assembled on glass substrates. Vib Spectrosc. 2004;34:37-45. 6- Gençoglu N, Oruçolu H, Helvacıolu D. Apical leakage of different guttapercha techniques: Thermafil, Js QuickFill, Soft Core, Microseal, System B and lateral condensation with a computerized fluid filtration meter. Eur J Dent. 2007;1:97-103.

7- Hillborg H, Ankner JF, Gedde UW, Smith GD, Yasuda HK, Wikstrom K. Crosslinked polydimethylsiloxane exposed to oxygen plasma studied by neutron reflectometry and other surface specific techniques. Polymer. 2000;41:6851-63.

8- Inan $U$, Aydemir $H$, Taşdemir T. Leakage evaluation of three different root canal obturation techniques using electrochemical evaluation and dye penetration evaluation methods. Aust Endod J. 2007;33:18-22.

9- Inan U, Aydin C, Tunca YM. In vitro evaluation of matched-taper single-cone obturation with a fluid filtration method. J Can Dent Assoc. 2009; 75:123-123c.
10- Kim S, Kratchman S. Modern endodontic concepts and practice: a review. J Endod. 2006;32:601-23.

11- Koch K, Barthlott W. Superhydrophobic and superhydrophilic plant surfaces: an inspiration for biomimetic materials. Philos Transact A Math Phys Eng Sci. 2009;367:1487-509.

12- Lin LM, Rosenberg PA, Lin J. Do procedural errors cause endodontic treatment failure? J Am Dent Assoc. 2005;136:187-93. 13- Matinlinna JP, Lassila LVJ, Urpo AY, Vallittu PK. An Introduction to silanes and their clinical applications in Dentristy. Int J Prosthodont. 2004;17:155-64.

14- Nair PN. Pathogenesis of apical periodontitis and the causes of endodontic failures. Crit Rev Oral Biol Med. 2004;15:348-81. 15- Namen FM, Ferrandini E, Galan Junior J. Surface energy and wettability of polymers light-cured by two different systems. J Appl Oral Sci. 2011;19:517-20.

16- Oliver CM, Timpawat S, Amornchat C, Trisuwan WR. Bacterial coronal leakage after obturation with three root canal sealers. J Endod. 2001;27:36-9.

17- Pashley EL, Tao L, Pashley DH. The sealing properties of temporary filling materials. J Prosthet Dent. 1988;60:292-7.

18- Piascik JR, Swift EJ, Thompson JY. Surface modification for enhanced silanation of zirconia ceramics. Dent Mater. 2009;25:1116-21.

19- Punia SK, Nadig P, Punia V. An in vitro assessment of apical micro-leakage in root canals obturated with gutta-flow, resilon, thermafil and lateral condensation: A stereomicroscopic study. J Conserv Dent. 2011;14:173-7.

20- Romieu OJ, Zimányi L, Warszyński P. Modeling colorant leakage techniques: application to endodontics. Dent Mater. 2010;26:881-90.

21- Siqueira JF Jr. Aetiology of root canal treatment failure: why well-treated can fail. Int Endod J. 2001;34:1-10.

22- Shanahan DJ, Duncan HF. Root canal filling using Resilon: a review. Br Dent J. 2011;211:81-8.

23- Schmage P, Sohn J, Ozcan M, Nergiz I. Effect of surface treatment of titanium posts on the tensile bond strength. Dent Mater. 2006;22:189-94.

24- Tay FR, Pashley DH. Monoblocks in root canals: a hypothetical or a tangible goal. J Endod. 2007;33:391-8.

25- Tian CS, Shen YR. Structure and charging of hydrophobic material/water interfaces studied by phase-sensitive sumfrequency vibrational spectroscopy. Proc Natl Acad Sci USA. 2009;106:15148-53.

26- Tummala M, Chandrasekhar V, Rashmi AS, Kundabala M, Ballal $V$. Assessment of the wetting behavior of three different root canal sealers on root canal dentin. J Conserv Dent. 2012;15:109-12. 27- Veríssimo DM, do Vale MS. Methodologies for assessment of apical and coronal leakage of endodontic filling materials: a critical review. J Oral Sci. 2006;48:93-8.

28- Yang C, Cheng K, Weng W, Yang C. OTS-modified HA and its toughening effect on PLLA/HA porous composite. J Mater Sci Mater Med. 2009;20:667-72.

29- Zamboni SC, Baldissara P, Pelogia F. Fatigue resistance of bovine teeth restored with resin-bonded fiber posts: effect of post surface conditioning. Gen Dent. 2008;56:56-9.

30- Zhang K, Kyung Y, Cadenaro M, Bryan TE. Effects of different exposure times and concentrations sodium hypochlorite/ ethylenediaminetetraacetic acid on structural integrity of mineralized dentin. J Endod. 2010;36:105-9. 